\title{
A Market Test for Natural Monopoly in Local Exchange
}

\author{
Sanford V. Berg \\ Department of Economics \\ University of Florida \\ Gainesville, Florida 32611 \\ John Tschirhart \\ Department of Economics and Finance \\ University of Wyoming \\ Laramie, Wyoming 82071
}

\begin{abstract}
Is the incumbent local exchange carrier (LEC) a natural monopolist? The analysis indicates that the LEC cost function is not supportable: LECs appear to be either nonsustainable natural monopolies or non natural monopolies over the set of services they currently offer. However, recent technological changes suggest that whether LECs are natural monopolies over their current offerings is immaterial for policy making, because competitors are enjoying economies of scope in offering both LEC and non $L E C$ services. Based on these results, deregulation of LECs is discussed in a Type I/Type II error framework.
\end{abstract}

December 8, 1994

\section{Introduction}

The divestiture of AT\&T marked the birth of the seven regional Bell Operating Companies (RBOCs). The rationale behind divestiture was that interexchange services were competitive and should be, in time, freed from regulation, but the RBOCs were natural monopolies and should remain 
under regulatory control. Entry into the RBOCs' local exchanges seemed unlikely. ${ }^{1}$ However, the persistent entry into the RBOCs' local exchanges over the past decade calls into question this natural monopoly rationale. Therefore, developing sound public policy for telecommunications infrastructure requires reexamining the question of whether RBOCs, or local exchange carriers (LECs), are natural monopolies. ${ }^{2}$ An affirmative answer suggests policies in line with the status quo: continued regulation with constraints on the activities of incumbent and entrant firms. A negative answer suggests relaxing regulatory rules and allowing the structure of the telecommunications industry to be shaped by market forces.

The issues are extremely complicated, requiring a careful delineation of the conceptual framework. The telecommunications services under consideration could include voice, data, information services, and video (among others). The delivery technologies range from traditional wireline via the copper twisted pair, to coaxial cable, fiber optics, and spectrum based technologies. The format can be analogue or digital. Thus, the answer to the question of whether a natural monopoly exists depends on which services are included or excluded, which technologies are considered applicable, and which formats are appropriate. It seems clear that the set of services, technologies, and formats relevant a decade ago differs from that available today.

Our objective is twofold: 1) to examine whether LECs are natural monopolies, and 2) to enumerate policy prescriptions that follow from 1), and from institutional realities. Our approach to 1) differs from previous work. We do not estimate a cost function and test it for subadditivity as a

${ }^{1}$ In 1983, Judge Greene wrote "There is no reason to believe that bypass on a large scale is imminent...", and four years later he reinforced this view. (Huber, et al., 1992)

${ }^{2}$ Although there are hundreds of LECs across the U.S., most of them are very small. We are concentrating on the seven RBOCs and GTE which is comparable in size to an RBOC. These eight firms serve about $90 \%$ of all telephone users. 
number of authors have done, albeit with mixed results. ${ }^{3}$ Nor do we offer a detailed discussion of LEC technology from which insights into natural monopoly status might be provided. ${ }^{4}$ Instead, we appeal to theoretical results on natural monopoly cost structures and sustainability to build a framework in which the question of natural monopoly status of LECs can be addressed. With the framework established, we use real world observations of market entry to draw some revealing conclusions about whether the LECs are natural monopolies.

Our findings can be summarized as follows. LECs appear to be either non sustainable natural monopolies or non natural monopolies with respect to the services they currently provide. However, further investigation reveals that some of the firms that compete with LECs by providing similar services, also provide other services, such as television (or mobile communications or interLATA toll), over which they enjoy economies of scope with the LEC services. The result is that these other services, such as television, must be brought into the set of goods offered by the LEC in order to formulate meaningful policies. This leaves the problem, however, of trying to determine whether a LEC is a natural monopoly over a set of goods it has never produced. The problem is complicated further by unknown consumer preferences and rapidly changing technologies.

\footnotetext{
${ }^{3}$ Interestingly, empirical evidence prior to divestiture did not support the natural monopoly claim, nor does most of the empirical evidence from the post divestiture period. The empirical studies have not been consistent, however. Christensen, Cummings and Schoech (1983) estimate a single output cost function, but the single output approach was rejected by subsequent authors. Evans and Heckman (1983) estimate a multiproduct cost function and reject the natural monopoly hypothesis. Using a very different approach (goal programming), Charnes, Cooper and Sueyoshi (1988) come to the opposite conclusion of Evans and Heckman which prompted a lively debate on the methodologies. Roeller (1990) modified the Evans and Heckman approach and also came to the opposite conclusion of Evans and Heckman. In a paper that discusses these earlier papers in more detail, Shin and Ying (1992) use more recent LEC data and reject the natural monopoly hypothesis.

${ }^{4}$ Several years ago, Greenwald and Sharkey (1989) addressed the natural monopoly question with a detailed discussion of LEC technology, and how changes in switching and other LEC capital equipment are reducing the likelihood that LECs are natural monopolies. They concluded, however, that although there has been an erosion of natural monopoly characteristics, the erosion is by no means complete. Nevertheless, they felt that partial regulation and regulatory reform could have substantial benefits to society.
} 
Any policy that is formulated should be forward looking, and the near future of telecommunications is a broadband and personal communications network whose structure will differ significantly from today's, but in ways yet unknown. An efficient structure is more likely to come about through open market forces and informed agents than through regulatory rules and less informed principals. Built into the regulatory process is a tendency to maintain the status quo. Status quo regulation encompasses waning rate-of-return regulation being replaced by profit sharing and forms of price capping, restrictions on intraLATA and interLATA competition and prohibitions against joint ownership of telephone and cable television services. ${ }^{5}$ But experience gained over the past decade suggests that in the Modification of Final Judgement (MFJ), the status quo is likely to mean an excessively costly transition from today's industry structure to tomorrow's. We propose transitional deregulation wherein status quo regulation is relaxed Concurrently, regulators would guard against excessive duplication of resources, and formulate new, alternative policies to achieve universal service.

The plan for the paper is as follows. The next section begins by developing a framework in which natural monopoly status can be examined. Then, within the framework, we make several observations of current market structure to draw conclusions about natural monopoly status of the LECs. The importance of defining the relevant set of services offered by the LECs is highlighted.

In Section 3, other factors that complicate the determination of natural monopoly status are outlined. These have to do with the simplicity inherent in polar case policies, consumer preferences, and product diversity. In addition, there is the widely accepted view that the telecommunications industry is about to undergo a major reconfiguration as broadband and wireless technologies emerge.

\footnotetext{
${ }^{5}$ Rural telephone companies are not prohibited from jointly providing cable television and telephone service, and they are excluded from our definition of LECs.
} 
We propose transitional deregulation as the appropriate policy in Section 4. We also note the similarity between the issues in today's telecommunications industry and the transportation industry of the 1930s. In hindsight, policy makers probably took the wrong turn in the 1930s by choosing more regulation. The tendency to make such a mistake in general is discussed in the context of Type I and Type II errors, and then related to telecommunications specifically. Section 5 is a very brief conclusion.

\section{Natural Monopoly}

\subsection{Framework}

The economic justification for price and entry regulation of a firm revolves around the concept of natural monopoly. ${ }^{6}$ A natural monopoly is said to exist when a firm's costs are subadditive over the relevant region of output; that is, when production by a single firm is less costly than production by multiple firms. This notion is the raison d'etre for studying natural monopoly, for it implies that if a firm is a natural monopoly, and if least-cost production is the social objective, then it should be the only firm in the industry. In this way the use society's scarce resources is minimized. But with only one firm there is no competition to promote an efficient allocation of resources across society. Thus, a firm that is a natural monopoly is a candidate for price and entry regulation through which competitive results might be mimicked.

However, determining whether regulation is justified requires two further pieces of information: first, are there barriers to entry into the firm's markets, and second, is the natural monopoly sustainable. ${ }^{7}$ If barriers to entry exist, which may be the result of large sunk costs that entrant firms must incur in order to begin producing, then regulation is justified. In this case

\footnotetext{
${ }^{6}$ Throughout, by regulation we will mean price and entry regulation; that is, prices are set by the regulatory agency, and entry into and exit from the industry are also controlled by this agency. Other types of regulation such as environmental or health and safety regulation are not being considered.

${ }^{7}$ See Baumol, Panzar and Willig (1982) or Braeutigam (1989) for support of this view.
} 
competitive forces are clearly absent and without regulation the natural monopolist could charge prices higher than and produce quantities smaller than the socially desirable prices and quantities. To avoid this situation, the regulator can set prices that maximize societal welfare, given that the firm must at least break even.

If barriers to entry do not exist, regulation may not be needed if the natural monopoly markets are contestable. A market is contestable when entry into and exit from the market by new firms is costless. If the natural monopolist's markets are contestable, the very threat of entry can play the same role as competition so that regulation may be unnecessary. ${ }^{8}$

Whether regulation is unnecessary in contestable markets depends on the second piece of information: Is the natural monopoly sustainable? A sustainable natural monopoly will be able to charge prices that will thwart entrants in all of its markets. A natural monopolist charging sustainable prices is taking advantage of its lower cost structure to deter potential entrants whose costs are at least as great. At the same time the natural monopolist cannot raise prices above those that allow it to break even, because to do so would invite the potential entrants to enter, charge lower prices in one or more markets, and take sales from the natural monopoly in those markets. Regulation is unnecessary because the natural monopolist is disciplined by market forces.

If the natural monopolist is not sustainable, then prices that thwart all entry do not exist. In spite of its cost advantages over potential entrants, the monopolist cannot find a set of prices that will thwart entry by higher cost producers. ${ }^{9}$ Because the natural monopoly cannot protect itself, it requires regulatory protection from entrants in order to ensure that products are obtained at least cost to society. Once the natural monopoly is protected, however, consumers must then be protected from high prices, and the regulator must again set prices.

\footnotetext{
${ }^{8}$ The theory of contestability is developed in Baumol, Panzar and Willig (1982).

${ }^{9}$ This counterintuitive result is associated with Zajac (1972) and Faulhaber (1975).
} 
These policies are summarized in table 1 where some additional cases are also noted. For example, in the bottom row, middle column, we have an impossible result. That is, a non natural monopoly will never have sustainable prices, and its markets will always be subject to entry. That a non natural monopoly cannot protect itself is reassuring, because it does not represent the least cost production. In three of the five possible boxes in table 1, regulation is not desirable, either because the firm is not a natural monopoly, or because the firm is a sustainable natural monopoly and regulation is not needed for protection from entry. In the remaining two boxes, regulation is justified either because consumers need protection from monopolistic pricing, or the natural monopoly needs protection from entrants so that society enjoys least cost production.

The above results are based on several implicit assumptions. First, that regulation itself is costless. If the act of regulating incurs large costs through administrative expenses, output and input distortions, or the stifling of innovation, then these costs would have to be weighed against the benefits of regulation. A second assumption is that deadweight loss incurred with unregulated monopoly pricing is large enough to warrant intervention. In small markets this may not be the case. Finally, table 1 designates polar cases. Many markets are not perfectly contestable, but also do not have insurmountable entry barriers. Policy prescriptions might then also fall in between those listed in the table. ${ }^{10}$

\subsection{Post Divestiture}

Table 1 lists optimum regulatory policies for a natural monopoly. However, from divestiture to the present these policies were never in place. Instead, the prevailing policy can best be described as partial regulation: a situation where some of the LEC's goods are subject to price and entry regulation and some are not. The popular rationale for partial regulation is similar to the rationale

\footnotetext{
${ }^{10}$ Baumol, Panzar and Willig (1982) emphasize that nonsustainability is not necessarily a prescription for regulatory protection if there are positive but not insurmountable entry barriers (p. 221).
} 
Table 1

Optimum Policies for Natural Monopolies

\begin{tabular}{|c|c|c|c|}
\hline & \multirow{2}{*}{$\begin{array}{l}\text { Barriers to Entry } \\
\text { (a) }\end{array}$} & \multicolumn{2}{|c|}{ No Barriers to Entry } \\
\hline & & (b) Sustainable & (c) Not Sustainable \\
\hline $\begin{array}{l}\text { 1. Natural } \\
\text { Monopoly }\end{array}$ & $\begin{array}{l}\quad(1 \mathrm{a}) \\
\text { Regulate to protect } \\
\text { consumers from } \\
\text { monopolistic prices. }\end{array}$ & $\begin{array}{l}\qquad(1 b) \\
\text { Do not regulate. } \\
\text { Allow threat of entry } \\
\text { to force break-even } \\
\text { prices. }\end{array}$ & $\begin{array}{l}\qquad(1 \mathrm{c}) \\
\text { Regulate to } \\
\text { protect NM from } \\
\text { entry, and then to } \\
\text { protect consumers } \\
\text { from monopoly } \\
\text { prices. }\end{array}$ \\
\hline $\begin{array}{l}\text { 2. non Natural } \\
\text { Monopoly }\end{array}$ & $\begin{array}{l}\qquad(2 \mathrm{a}) \\
\text { Break up firm } \\
\text { through antitrust } \\
\text { action. } \\
\text { Do not regulate. }\end{array}$ & $\begin{array}{l}(2 \mathrm{~b}) \\
\text { Impossible }\end{array}$ & $\begin{array}{l}\qquad(2 \mathrm{c}) \\
\text { Do not regulate. } \\
\text { Let market } \\
\text { structure be } \\
\text { dictated by market } \\
\text { forces. }\end{array}$ \\
\hline
\end{tabular}


for divestiture. That is, some of the LEC's outputs are sold in potentially competitive markets so regulation can be relaxed. But the remaining outputs are sold in non competitive, core markets where entry is unlikely. Continued regulation is called for to protect the core consumers.

Under partial regulation, four outcomes are possible: 1) a sustainable or non sustainable natural monopoly losing one or more of its markets to entrants, 2) a sustainable or non sustainable natural monopoly retaining all its markets and earning nonnegative profit, 3) a non natural monopoly being sustainable under partial regulation and retaining all its markets, and 4) a non natural monopoly losing one or more of its markets. ${ }^{11}$

The first outcome comes about when products in regulatory protected markets receive cross subsidies from markets open to competition. A standard cream skimming exercise ensues with competitors preying on the subsidizing markets. The entry into the natural monopoly markets is economically inefficient.

The second outcome occurs when a totally regulated natural monopoly charging sustainable prices becomes partially regulated and gains price flexibility in the competitive markets. (The regulated prices are assumed to remain the same.) The firm can raise its prices in the competitive markets up to just below the competitors' prices. The firm's profit increases above zero. The firm can raise its prices without losing markets, because the incremental costs of its competitive products is less than the incremental costs of its competitors. The competitors' incremental costs are the natural monopolist's stand-alone costs, and by the characteristics of natural monopoly, the natural monopoly's incremental costs are less than its stand-alone costs.

The third outcome follows when there are cross subsidies from the regulated markets to the competitive markets. Competitors cannot compete with subsidized prices in the competitive markets, and entry does not occur in the regulated markets because they are protected. Although non natural

\footnotetext{
${ }^{11}$ Details on these outcomes are in Berg and Tschirhart (1988) or Tschirhart (1989).
} 
monopolies are not sustainable without government intervention, they can be sustainable under the partial regulation scenario.

The fourth outcome is straightforward. The non natural monopoly does not have sustainable prices, and regulators do not help, inadvertently or otherwise, as in outcome three by setting high prices in the protected markets. The firm loses at least some of its markets, and this benefits society because multifirm production is less costly.

\subsection{Implications for Natural Monopoly Status}

The procedure is to observe current LEC experience, and determine whether it is consistent with one and only one of the four outcomes under partial regulation. If it is, then whether the LEC is a natural monopoly can be ascertained. For specificity, the observations will be cast in terms of an LEC offering plain old telephone service (POTS), business service (BUSINESS) and voice messaging (MESSAGE). ${ }^{12}$ POTS is the regulated core service usually equated with residential service; ${ }^{13}$ BUSINESS is a regulated service which differs from POTS owing to much higher volumes at both

${ }^{12}$ LECs offer more than three products. In this example, BUSINESS is being used to represent a broad set of regulated, non core services, and MESSAGE is being used to represent a broad set of unregulated services sold in competitive markets.

${ }^{13}$ Here we combine access and usage into POTS. However, we are convinced that it is reasonable to treat access and usage as separate services. Kahn and Shew (1987) lay out the arguments quite clearly. Some economists disagree--see Copeland and Severn (1985). In Parson's 1994 update on the debate, he shows that the case for separate services still remains strong. He notes that there are different incremental costs associated with access and usage: "Cross-elastic or spill-over revenue effects and producer costs are independent economic phenomena." (p. 159). Since our basic analysis groups these together into POTS, we do not draw upon the distinction in considering sustainability of pricing.

Note that if we further broke $\mathbf{y}_{\mathrm{p}}$ into three services (access, local usage, and long distance usage), the force of our arguments would be stronger, since now we would have to consider costs over a wider range of services. ATT-McCaw will be competing in the local exchange market; LECs are surely potential competitors in the interLATA (long distance) market. The market test for natural monopoly suggests even more strongly that LECs are not natural monopolists over an expanding number of services! Instead of focusing on television as the "new" service, we could have included interLATA toll calls or mobile services in our analysis. 
the local and interexchange levels, and the need for data transmission; and MESSAGE is a nonregulated service sold in a clearly competitive market. Assuming MESSAGE is not regulated and sold in a competitive market is consistent with the partial regulation paradigm that has prevailed since divestiture.

Let the quantities of POTS, BUSINESS and MESSAGE produced by the LEC be represented by $y_{p}, y_{b}$ and $y_{m}$, respectively. The total cost of producing the three goods is given by the function

$$
C\left(y_{p}, y_{b}, y_{m}\right) \text {. }
$$

The stand-alone costs for producing any one good are

$$
C\left(y_{p}, 0,0\right), C\left(0, y_{b}, 0\right) \text { and } C\left(0,0, y_{m}\right) \text {, }
$$

and the stand-alone costs for producing any two goods are

$$
C\left(y_{p}, y_{b}, 0\right), C\left(y_{p}, 0, y_{m}\right) \text { and } C\left(0, y_{b}, y_{m}\right) \text {. }
$$

Assumption 1. All firms in the industry have access to the same technologies.

Bain (1992) argues that there are no proprietary technologies. This is true in part because a major source of technology, Bell Labs, was required in 1956 to license its patents at nominal fees to all parties. Thus, the above cost function can be used for the LEC or for entrants. For example, if a firm entered and offered BUSINESS only, its cost would be $C\left(0, y_{b}^{e}, 0\right)$, where $y_{b}^{e}$ is the entrant's quantity.

Let the LEC prices of $y_{p}, y_{b}$ and $y_{m}$ be denoted by $p_{p}, p_{b}$ and $p_{m}$, respectively. Prices for POTS and BUSINESS are determined through the regulatory process, but MESSAGE is unregulated. Assumption 2: The LEC is a price taker in the competitive market. The LEC produces at least as much of MESSAGE as any competitor, and competitors earn zero profit, or

$$
\mathrm{p}_{\mathrm{m}} \mathrm{y}_{\mathrm{m}}^{\mathrm{c}}=\mathrm{C}\left(0,0, \mathrm{y}_{\mathrm{m}}^{\mathrm{c}}\right) \text { for } \mathrm{y}_{\mathrm{m}}^{\mathrm{c}}<\mathrm{y}_{\mathrm{m}} \text {. }
$$


Assumption 2 is similar to assumptions used in other models of partial regulation. ${ }^{14}$

Assumption 3: The LEC earns zero profit under partial regulation, or

$$
p_{p} y_{p}+p_{b} y_{b}+p_{m} y_{m}=C\left(y_{p}, y_{b}, y_{m}\right) \text {. }
$$

Assumption 3 is commonly used in models of total regulation. In a partial regulation framework, the Assumption follows if the regulator is successful in ensuring that there are no cross subsidies between the competitive and regulated markets. To this end, a common regulatory practice is to take any competitive revenues in excess of the competitive costs, and add them to the revenue requirement for the regulated goods. Of course, whether the competitive costs are incremental costs or some type of fully distributed costs will be crucial for whether the regulator actually avoids cross subsidies. Regardless, LEC ventures into unregulated competitive markets is still a small part of their total business so that Assumption 3 seems relatively innocuous.

The first observation is that LECs are losing market share (being bypassed) in some of their markets. This seems noncontroversial: the question is why. The bypass indicates that there are no insurmountable barriers to entry. Moreover, outcomes 2) and 3) under partial regulation can be eliminated as explanations for the observation. Both of these outcomes had the firm retaining all its markets, but this is inconsistent with the observed entry. This leaves outcomes 1) and 4), and the observed entry is consistent with both.

The second observation is that some users of BUSINESS are bypassing the LECs and obtaining service from competitive access providers (CAPs). CAPs install fiber optic cables that allow high volume businesses direct access to interexchange carriers or each other without using any of the LEC's facilities. ${ }^{15}$ Metropolitan Fiber Systems is the largest CAP, serving eleven major cities. The number

\footnotetext{
${ }^{14}$ See Braeutigam and Panzar (1989) or Brennan (1990) for examples.
}

${ }^{15} \mathrm{LECs}$ also provide access or the delivery of long-distance traffic to and from end users. About $30 \%$ of LEC revenues in 1990 derived from interexchange carrier access payments (U.S. Telephone Association, Phone Facts 1991), although this number is falling with the proliferation of CAPs. 
of CAPS has grown dramatically over the last five years, with seventy-one large cities being served by sixty different firms. ${ }^{16}$ Observation two is formalized as:

$$
\mathrm{p}_{\mathrm{b}}>\mathrm{p}_{\mathrm{b}}^{\mathrm{e}}, \mathrm{y}_{\mathrm{b}}^{\mathrm{e}}<\mathrm{y}_{\mathrm{b}} \text { and } \mathrm{p}_{\mathrm{b}}^{\mathrm{e}} \mathrm{y}_{\mathrm{b}}^{\mathrm{e}} \geq \mathrm{C}\left(0, \mathrm{y}_{\mathrm{b}}^{\mathrm{e}}, 0\right)
$$

$\mathrm{C}\left(0, \mathrm{y}_{\mathrm{b}}^{\mathrm{e}}, 0\right), \mathrm{p}_{\mathrm{b}}^{\mathrm{e}}$ and $\mathrm{y}_{\mathrm{b}}^{\mathrm{e}}$ are the CAP cost, price and quantity, respectively. The CAP price must undercut the LEC price for BUSINESS in order for the CAP to enter. This is perhaps stronger than necessary, because if the prices were equal, some entry is still likely. ${ }^{17}$ However, even with a lower price the CAP does not take away the entire market from the LEC. The transactions cost of switching to a new provider, or perhaps brand loyalty, means that the majority of users remain with the LEC. At least this is what has occurred to date. The quantities of BUSINESS demanded will depend on both the LEC and CAP prices, and this dependency can be written as $y_{b}\left(p_{b}, p_{b}^{e}\right)$ and $\mathrm{y}_{\mathrm{b}}^{\mathrm{e}}\left(\mathrm{p}_{\mathrm{b}}, \mathrm{p}_{\mathrm{b}}^{\mathrm{e}}\right)$. Demands for BUSINESS are assumed to be independent of the demands for POTS and MESSAGE. For notational convenience, the price arguments in the demand functions will continue to be omitted.

The third observation is that CATVs are poised to begin offering POTS (or a close substitute) to residential users. CATVs are connected to residential users with coaxial cable. They have grown dramatically over the last decade, and cables now pass about $95 \%$ of U.S. households with $62 \%$

Interexchange carriers commonly bundle their long-distance service with CAP access (Huber, et al.). Thus, when a business user bypasses the LEC to go with a CAP, we have it bypassing LEC access as well. For this reason we have not included access in the model as a separate, fourth good. This is a simplification, because there may still be fixed charges for the IXC that are not avoided. A good discussion of the controversy over whether access is a bottleneck can be found in Huber, et al.

${ }^{16}$ See Kinzler, Ruiz and Woroch (1992) for a summary of CAP penetration.

${ }^{17}$ Telecommunications managers in the Bell Atlantic area were asked whether they would switch any of their business to a CAP if the price and reliability were the same as Bell Atlantic's. The response was that $22 \%$ would not shift at all, $18 \%$ would shift $1 / 4$ th of their traffic, $35 \%$ would shift $1 / 2,9 \%$ would shift $3 / 4$ th and $16 \%$ would shift all traffic. (Gross, 1992) 
actually subscribing. ${ }^{18}$ In England, television and telephone are already being offered over a single line. Of course, cable companies there have utilized siamic cables which combine coaxial for TV with twisted copper pairs for telephony. Additional electronics, use of the spectrum or other technologies will have to be utilized in the U.S. ${ }^{19}$

To illustrate the pace of technological developments, note that the recent Cable Television Laboratories (CTL) request for information on telephone services via cable, video telephony, and personal communications systems (PCS) elicited responses from over 70 vendors. A CTL Request for Proposals on POTS is expected to yield further research activity: "Remaining technical issues include powering the cable plant for telephony, fine-tuning the size of the house network interface unit, and finalizing the preferred modulation methods to send a variety of types of data (circuit or packet-switched; voice, video, and data) across a limited return path." (Karpinski, 1994, p. 24) Additional strategies available to cable include partnerships with electric utilities, expansion into competitive access (half the CAP industry is owned by cable), entry into niche markets (such as data services to business, Internet access, or fax mail), entry into PCS (where Time Warner has already completed a technology trial involving PCS over cable in conjunction with a microcell system), and the provision of second and third lines. Although this discussion illustrates points using examples

${ }^{18}$ National Cable Television Association, Cable Television Developments, Nov. 1993.

${ }^{19}$ We do not maintain that the incremental costs are zero for cable provision of telephony--just that they are coming down rapidly enough to put competitive pressures on LECs. Leland Johnson (1994) argues that cable companies can more easily upgrade their networks with fiber to exploit economies of scope than can LECs (p. 28) "If the integrated broadband network to the home does emerge, it may trace its beginnings to the cable industry rather than to the telephone industry." (p. 35) He maintains that the rapid rate of technological progress in this area is bringing costs down. Digital compression also permits substantial savings. There are potential complications: "In addition to government regulatory hurdles, cable operators face potential technical difficulties in providing narrowband services. The tree-and-branch cable topology may be susceptible to signal interference that, without costly upgrading, could reduce the quality of telephone service to unacceptable levels. Further, the ability of cable networks to supply telephone service at today's high levels of reliability remains to be assessed. Finally, difficulties may emerge in provision of custom calling features on treeand-branch networks." (p. 37). 
from cable, the same chain of reasoning applies to ATT-McCaw (wireless) entry into POTS -- where the fourth service is mobile communications rather than TV.

CATVs are restructuring their distribution from a "tree and branch" network to a "star" network which will allow more efficient use of fiber optics as a connection to their coaxial cables. New decentralized switching technologies and rules for interconnection lower the costs of CATV entry into local service. Because coaxial cable has 250,000 times the capacity of the LEC's copper wires, the CATVs are in a better position to offer POTS than the LECs are to offer television (Gilder, 1992). ${ }^{20}$ Observation three is formalized similar to observation two:

$$
\mathrm{p}_{\mathrm{p}} \geq \mathrm{p}_{\mathrm{p}}^{\mathrm{e}}, \mathrm{y}_{\mathrm{p}}^{\mathrm{e}}<\mathrm{y}_{\mathrm{p}} \text { and } \mathrm{p}_{\mathrm{p}}^{\mathrm{e}} \mathrm{y}_{\mathrm{p}}^{\mathrm{e}} \geq \mathrm{C}\left(\mathrm{y}_{\mathrm{p}}^{\mathrm{e}}, 0,0\right) \text {. }
$$

$\mathrm{C}\left(\mathrm{y}_{\mathrm{p}}^{\mathrm{e}}, 0,0\right), \mathrm{p}_{\mathrm{p}}^{\mathrm{e}}$ and $\mathrm{y}_{\mathrm{p}}^{\mathrm{e}}$ are the CATV cost, price and quantity for POTS, respectively. The price of POTS offered by CATVs is yet known, but it is expected to be competitive with the price of POTS offered by LECs. ${ }^{21}$ And, as was the case with BUSINESS, entry is modelled as cooperative, with the CATV taking less than a majority of the users.

Note that this analysis only considers the current set of LEC service offerings (here represented by three services). Typically, when analysts examine whether or not a firm is a natural monopoly, they look at current offerings of that firm and then ask what are the potential competitors' costs of offering those services. They do not examine economies of scope that competitors enjoy with other products. Such limited analysis can lead to incorrect conclusions regarding subadditivity or the natural monopoly status of the incumbent. This is a particularly important oversight in the telecommunications situation since competitors, such as cable companies, do enjoy economies of scope over telephony and television. To demonstrate this, we first examine the industry in a typical

\footnotetext{
${ }^{20}$ Riordan (1992) presents an interesting theoretical model of technology adoption by an LEC and a CATV under varying regulatory and technological conditions.

${ }^{21}$ Cramer (1994) suggests the monthly charge can be as low as $\$ 10$.
} 
fashion and draw conclusions. These results are then revised in the next section where we correctly formulate the problem to incorporate appropriate economies of scope for potential entrants. ${ }^{22}$

Substituting Assumption (1) and the second and third observations ((3) and (4)) into Assumption (2) yields

$$
\mathrm{C}\left(\mathrm{y}_{\mathrm{p}}^{\mathrm{e}}, 0,0\right)\left[\mathrm{y}_{\mathrm{p}} / \mathrm{y}_{\mathrm{p}}^{\mathrm{e}}\right]+\mathrm{C}\left(0, \mathrm{y}_{\mathrm{b}}^{\mathrm{e}}, 0\right)\left[\mathrm{y}_{\mathrm{b}} / \mathrm{y}_{\mathrm{b}}^{\mathrm{e}}\right]+\mathrm{C}\left(0,0, \mathrm{y}_{\mathrm{m}}^{\mathrm{c}}\right)\left[\mathrm{y}_{\mathrm{m}} / \mathrm{y}_{\mathrm{m}}^{\mathrm{c}}\right]<\mathrm{C}\left(\mathrm{y}_{\mathrm{p}}, \mathrm{y}_{\mathrm{b}}, \mathrm{y}_{\mathrm{m}}\right) .
$$

Inequality (5) indicates that the LEC cost function is not supportable. (Sharkey, 1982, p. 93) The lack of supportability yields two useful conclusions. First, because supportability is a necessary condition for sustainability, the LEC is not sustainable. Second, because supportability is a stronger condition on cost functions than is subadditivity, the LEC may or may not exhibit subadditive costs, and, therefore, may or may not be a natural monopoly. ${ }^{23}$ That the LEC may be a nonsustainable natural monopoly is consistent with outcome 1) under partial regulation, and that the LEC may be a non natural monopoly is consistent with outcome 4). Although nonsustainable natural monopoly may be an unlikely scenario (See Baumol, Panzar and Willig, 1982, p. 223) it cannot be ruled out. ${ }^{24}$

${ }^{22}$ In determining whether or not a firm is a natural monopoly in the long run, economists assume that there are no fixed (or sunk) costs. Recognition of the dramatic changes in technologies and services makes the determination of a long run ("static") natural monopoly over all these services irrelevant for the purpose of policy development.

${ }^{23}$ According to Sharkey (1982), the lack of supportability implies that the cost function is neither subadditive and convex nor subadditive and linearly homogeneous, but subadditivity alone cannot be ruled out. For more on the relationships between supportability, sustainability and anonymous equity, see Faulhaber and Levinson (1981), Mirman, Tauman and Zang (1985), Spulber (1989), or for a summary of the literature, Mitchell and Vogelsang (1991).

${ }^{24}$ To be clear, the question of natural monopoly status is with respect to all three goods, POTS, BUSINESS and MESSAGE. There are no implications here as to whether some proper subset of these three goods is a natural monopoly. For example, could POTS by itself or BUSINESS by itself be a natural monopoly? If so, this would require refocusing the current policy debate, because there is no discussion concerning divesting LECs into separate companies, one providing traditional telephony and the other data transmission. 
If the LEC is a non natural monopoly or a nonsustainable natural monopoly, then optimum policy from table 1 indicates deregulation or regulatory protection from entrants, respectively. ${ }^{25}$ However, basing regulatory policy on the natural monopoly status of LECs' with respect to their current service offerings is in error and likely to fail. The reasoning follows.

\subsection{Technology Driven Policies}

The conclusions derived concerning the LEC's natural monopoly status over POTS, BUSINESS and MESSAGE relied, in part, on the CATVs' costs $C\left(\mathrm{y}_{\mathrm{p}}^{\mathrm{e}}, 0,0\right)$. As written, this cost is the stand-alone cost of POTS for an entrant CATV. However, CATVs also offer television - in fact, it is their principal offering. The technological changes in decentralized switching and digital formatting are enabling the CATV to move into POTS and probably enjoy substantial economies of scope in doing so. Because the CATV cost of offering POTS will depend on the quantity of TV offered, the CATV cost must be written as

$$
\mathrm{C}\left(\mathrm{y}_{\mathrm{p}}^{\mathrm{e}}, 0,0, \mathrm{y}_{\mathrm{t}}^{\mathrm{e}}\right)
$$

where $\mathrm{y}_{\mathrm{t}}^{\mathrm{e}}$ is the quantity of television (TV). With this formulation, the above conclusions that LECs are either non natural monopolies or nonsustainable natural monopolies over POTS, BUSINESS and MESSAGE becomes premature. More importantly, however, the question of whether the LECs are natural monopolies over their current services is immaterial. The germane question is whether the LECs are natural monopolies over POTS, BUSINESS, MESSAGE and TV.

\footnotetext{
${ }^{25} \mathrm{~A}$ complication is that CAPs are providing a service that is not a complete substitute for business users, because these users do not have access to the LECs local loop. Thus, a user can communicate with other large businesses or go through the interexchange carrier, but could not call home on the CAP system. The problem becomes one of pricing LEC inputs sold to competing CAPs. See Panzar (1980), Baumol and Sidak (1994), and Kahn and Taylor (1994) for more on this issue. For of the model, we could split business demands into business calls and local non business calls and assume that CAPs are providing just the former service while CATVs will be providing the latter with POTs. This is realistic, because CAPs and CATVs are entering joint ventures with the prospect of completely duplicating the LECs' networks. See Huber, et al. (1992, p. 2.57) for many examples.
} 
To see how cost as depicted in (6) alters the situation, consider that the CATV need only cover incremental cost to make POTS viable. Substituting incremental cost for stand-alone cost in (4) yields

$$
\mathrm{p}_{\mathrm{p}} \geq \mathrm{p}_{\mathrm{p}}^{\mathrm{e}}, \mathrm{y}_{\mathrm{p}}^{\mathrm{e}}<\mathrm{y}_{\mathrm{p}} \text { and } \mathrm{p}_{\mathrm{p}}^{\mathrm{e}} \mathrm{y}_{\mathrm{p}}^{\mathrm{e}} \geq \mathrm{C}\left(\mathrm{y}_{\mathrm{p}}^{\mathrm{e}}, 0,0, \mathrm{y}_{\mathrm{t}}^{\mathrm{e}}\right)-\mathrm{C}\left(0,0,0, \mathrm{y}_{\mathrm{t}}^{\mathrm{e}}\right)
$$

Using (7) as observation three and substituting it into (5) yields

$$
\begin{gathered}
\mathrm{C}\left(\mathrm{y}_{\mathrm{p}}^{\mathrm{e}}, 0,0, \mathrm{y}_{\mathrm{t}}^{\mathrm{e}}\right)\left[\mathrm{y}_{\mathrm{p}} / \mathrm{y}_{\mathrm{p}}^{\mathrm{e}}\right]+\mathrm{C}\left(0, \mathrm{y}_{\mathrm{b}}^{\mathrm{e}}, 0,0\right)\left[\mathrm{y}_{\mathrm{b}} / \mathrm{y}_{\mathrm{b}}^{\mathrm{e}}\right]+\mathrm{C}\left(0,0, \mathrm{y}_{\mathrm{m}}^{\mathrm{c}}, 0\right)\left[\mathrm{y}_{\mathrm{m}} / \mathrm{y}_{\mathrm{m}}^{\mathrm{c}}\right] \leq \\
\mathrm{C}\left(\mathrm{y}_{\mathrm{p}}, \mathrm{y}_{\mathrm{b}}, \mathrm{y}_{\mathrm{m}}, 0\right)+\mathrm{C}\left(0,0,0, \mathrm{y}_{\mathrm{t}}^{\mathrm{e}}\right)\left[\mathrm{y}_{\mathrm{p}} / \mathrm{y}_{\mathrm{p}}^{\mathrm{e}}\right]
\end{gathered}
$$

Both the left and right sides of (8) present alternative industry structures for producing the same quantities of all four goods. However, (8) has no implications for the supportability or natural monopoly status of LECs or any of the other firms.

The conclusion that the LEC is either a non natural monopoly or a nonsustainable natural monopoly is no longer valid in this new formulation. The LEC could very well be a sustainable natural monopoly over POTS, BUSINESS and MESSAGE and charging sustainable prices, yet still be losing markets. If the CATV realizes greater economies of scope when producing POTS than does the LEC, then this could be driving the result that a sustainable natural monopoly over POTS, BUSINESS, and MESSAGE in the absence of TV is not sustainable in the presence of TV. More specifically, the result follows if CATV's average incremental cost of POTS is less than the LEC's average incremental cost of POTS.

To demonstrate, suppose the CATV sets its price for POTS equal to the average incremental cost so that the last inequality in (7) is an equality. Such a price is consistent with zero profit and no cross subsidies for the CATV. The LEC can charge no more than this price to retain its share of the market. If the LEC matches the CATV price, then

$$
\begin{array}{r}
\mathrm{p}_{\mathrm{p}}=\left[\mathrm{C}\left(\mathrm{y}_{\mathrm{p}}^{\mathrm{e}}, 0,0, \mathrm{y}_{\mathrm{t}}^{\mathrm{e}}\right)-\mathrm{C}\left(0,0,0, \mathrm{y}_{\mathrm{t}}^{\mathrm{e}}\right)\right] / \mathrm{y}_{\mathrm{p}}^{\mathrm{e}}< \\
{\left[\mathrm{C}\left(\mathrm{y}_{\mathrm{p}}, \mathrm{y}_{\mathrm{b}}, \mathrm{y}_{\mathrm{m}}, 0\right)-\mathrm{C}\left(0, \mathrm{y}_{\mathrm{b}}, \mathrm{y}_{\mathrm{m}}, 0\right)\right] / \mathrm{y}_{\mathrm{p}}}
\end{array}
$$


Expression (9) shows that the LEC's price is equal to the CATV's average incremental cost for POTS which, by assumption, is less than the LEC's average incremental cost. ${ }^{26}$ However, the LEC's price in (9) is nonsustainable, because if the revenue from POTS is not enough to cover the incremental cost of POTS, then POTS is being cross subsidized. A necessary condition for sustainability is that there be no cross subsidies. (Panzar and Willig, 1977)

While the LEC may have been a natural monopoly over POTS, BUSINESS and MESSAGE, this is no longer relevant because technology has brought television into the picture. Technological advances force the inclusion of television in the set of goods that must be considered when designing regulatory policies.

\section{Further Complications}

\subsection{Deficiencies of Polar Case Policies}

To formulate sound policy, the germane question is whether the LEC is a natural monopoly over POTS, BUSINESS, MESSAGE and TV. But a preliminary question could be: "Can the germane question be answered?" The above analysis does not provide an unambiguous answer. Estimating cost functions and testing for subadditivity also is unlikely to provide an answer. When cost functions were estimated for LECs in the past, and the outputs were the current set of regulated products, the results were mixed. ${ }^{27}$ Estimating cost functions over both regulated and unregulated outputs, and over outputs provided by CAPs and CATVs - unregulated firms not required to provide data - would yield no better than mixed results.

Moreover, even if the germane question could be answered, the polar case policy prescriptions from table 1 would not be useful. Consider that the prescriptions depend on natural monopoly status,

\footnotetext{
${ }^{26}$ Jamison (1994) provides an example similar to this in order to demonstrate the affect of nontraditional suppliers entering public utility markets. Some of his conclusions parallel those in this paper about needing to include these other suppliers in formulating policy.

${ }^{27}$ See endnote 3 .
} 
barriers to entry and sustainability. If the LEC is not a natural monopoly, deregulation is appropriate. But the presence of low-volume core customers and rural customers, and the tradition of universal service suggest that deregulation is too abrupt. If the LEC is a natural monopoly, and knowing from observations that there are not barriers to entry, appropriate policy would hinge on sustainability. If the LEC is sustainable, deregulation is again appropriate, and again too abrupt. If the LEC is not sustainable, least-cost supply suggests that the LEC should be protected from entry. But this would require barring CAPs from an industry in which they have already made substantial investments, and barring CATVs from television. Neither of these actions could be taken seriously.

\subsection{Preferences, Quality and Diversity}

Added to the difficulty of determining natural monopoly status are several other complications that are noteworthy. The literature has begun to emphasize the roles of consumer preferences and output quality as determinants of a natural monopoly. Shaked and Sutton (1982), Sutton (1986) and

Gabszewicz et al. (1986) have explored how the structure of demand and the income distribution can lead to a natural monopoly when the cost of quality improvements is incorporated into the analysis. It is possible that a market becomes dominated by a single supplier because "...customers who differ in the horizontal characteristics they prefer may all be captured by one product through significantly large improvements in the vertical quality component." (Waterson, 1987, p. 77). The key issue for natural monopoly is whether such vertical quality improvements depend on expenditures on fixed or variable costs. If it is the latter, the industry could be transformed into a competitive one, where numerous suppliers of high quality services compete for business. Alternatively, if quality improvements require sunk capital costs, then a natural monopoly may emerge because of the preference patterns.

New product or service introductions can play a role similar to quality in creating or destroying subadditivity if the relevant set of services changes. The example from above in which the 
set of services was expanded to include television, illustrates this point. Add mobile communications to the set as a fifth service (via cellular and personal communications networks), consider possible substitutions and complementarities, and natural monopoly status becomes even more difficult to determine. Some observers see wireless technology as dominating many markets and applications of future network infrastructures. (Egan, 1994) In fact, the entire discussion of Section 2 could have been based on POTS entry via the radio spectrum, with mobile telephony as the fourth service. (Calhoun, 1992)

The four-good example above is also a simplification with respect to the diversity of services that must be taken into account in an evaluation of the potential for natural monopoly. For example, BUSINESS is not a homogeneous good comprising "local network services." A wide range of customized features characterize the market. The resulting service diversity can be labeled as horizontal differentiation, since business customers will differ in their willingness to pay for the features.

These diverse services are made possible by technological innovations. Cabe (1990) argues that changes in demand imply that we need to balance the benefits of diversity against the benefits of large scale production by a single supplier:

The growing value attached to telecommunications services and the expanding range of functions they are called on to perform leads to a growing differentiation of demand according to the characteristics of the telecommunications product or service. The sorts of characteristics which become important include: bandwidth or capacity, geographic location, network intelligence, mobility, compatibility... with existing applications and forward compatibility with anticipated future needs, durability or longevity of equipment or contracts, reliability, network scope, error rate or transmission quality, and blocking probability. (Cabe, 1990, pp. 2-3)

Customization has costs as well as benefits, however. Supply side changes (described above in the case of quality) make possible demand side changes. Innovations make differentiation possible. The question is how regulation will respond to these commercial opportunities: restrict entry by new firms or constrain prices and limit service offerings by incumbent firms. 


\subsection{Technological Change and Broadband}

The analysis above can be used to show how given technological changes can transform a potentially competitive industry into a natural monopoly or vice versa. However, the analysis conveys little of the flavor of the reward structures facing the innovators. Technological change is not exogenous. There certainly are strong elements of unpredictability in the research and development process, but economic conditions affect the rate and pattern of $\mathrm{R} \& \mathrm{D}$ investment.

The dramatic pace of technological change in telecommunications over the past decade provides an impetus for policy makers to reassess whether LECs are natural monopolies. But Section 2 illustrated that whether the LECs are natural monopolies over their current set of goods is immaterial, because changing technology has forced the inclusion of TV into the set of goods. Including TV is just a first step, however, because profound changes in telecommunications lie just ahead. Broadband telecommunications and wireless are the systems of the near future, and policy making should center on this reality. ${ }^{28}$

The broadband network will be a significantly reconfigured industry. Although there is no consensus on what form the reconfiguration will take, most analysts seem to agree on several key components. End users will have either coaxial or fiber droplines, depending on whether fiber is taken to the curb or home. The backbone will be fiber gathered at remote terminals, and then capacity will be shared to central offices. Switching will be decentralized. In rural areas having low user density, change will be slower. Twisted copper and narrowband service may remain the only option for some remote users. There will also be wireless personal communications networks (PCNs) that may compete with landlines or which may be viewed by end users as a complementary or

${ }^{28}$ To formulate today's policies we should be looking at tomorrow's technology and avoid the ignominy that "Lawyers and economists, like aging generals, seem fated always to fight the last war rather than the next." (Huber, Kellogg and Thorne, 1992, p. 1.42) 
substitute service. PCNs, because of their need for small cells and numerous antennas, also will be less prevalent in rural areas.

What is less clear than the envisioned technologies is whether there will be multiple providers of broadband, perhaps with duplication of local loops in the same way that interexchange carriers have duplicated long distance fiber optics. ${ }^{29}$ Will CATVs and LECs merge to take advantage of each others' technology and experience? Will CAPs be so plentiful and so lacking in scale economies as to produce a truly competitive local marketplace? Will PCN be offered by LECs, independents, or some merged pairs? The answers to these questions depend on regulatory policies in the years ahead.

\section{Policy Choices under Uncertainty}

\subsection{Transitional Deregulation}

Presently, there is no single type of firm that is poised to dominate the markets. Consider, for example, that in 1992 CAPs had a $0.3 \%$ share of the U.S. LEC markets and have largely been confined to providing special access in the markets they have entered. Yet, where competition with the LECs has been ongoing for three or more years, CAP market shares of 20 to 30 percent are common. CAP revenues increased 91 percent from 1991 to 1992, and in several major markets over half of the new circuits installed are with CAPs. ${ }^{30}$ As CAPs are permitted collocation, these numbers could grow substantially. ${ }^{31}$

\footnotetext{
${ }^{29}$ Huber (1993) contends that long distance is where the natural monopoly is, because the interexchange carriers have substantial excess capacity in their fiber-optic cables that serve the same regions.

${ }^{30}$ See Cramer (1994) for more detail on the figures concerning CAPs.

${ }^{31}$ Collocation refers to allowing the CAPs to physically locate their facilities at the LECs' central offices and interconnect with the LECs' switches.
} 
The contrast between LECs and CATVs is also noteworthy. Annual revenues for the CATVs and LECs are about $\$ 20$ billion and $\$ 100$ billion, respectively. As indicated by Cramer (1994):

In the case of the existing cable TV network, the percentage of investment is $6 \%$ in the home office, $19 \%$ in trunks, and $75 \%$ in coaxial cable distribution. For the existing telephone company network the configuration is $13 \%$ in the central office, $33 \%$ in feeders, and $54 \%$ in distribution. For cable TV to move to a broadband communications network, only $19 \%$ of installed base requires replacement with fiber trunk and neighborhood hubs. Telephone companies must replace feeder and distribution, which is $87 \%$ of the installed base, to create a broadband network.

If both CATVs and LECs duplicate each others' distribution systems so that both provide broadband service, the investments will be substantial. The recent merger between US WEST and Time-Warner and the failed acquisition of TCI by Bell Atlantic, therefore, suggest attempts to realize economies of scope by avoiding wasteful duplication.

Currently, industry participants are investing in new local markets with new technologies. From the perspective of maximizing societal welfare, those investments should occur in the most efficient technologies, namely, those that will allow a welfare-maximizing transition for the telecommunications industry. But the uncertainties surrounding the industry's future make choosing the most efficient investments extremely difficult. The source of the uncertainties, however, are not purely technological. The willingness of consumers to pay for new services is unclear. One of the benefits of multiple centers of initiative in the new industry is the exploration of consumer preferences through marketing experiments. In addition, unclear or changing regulatory policies contribute significantly to uncertainty. Unfortunately, regulatory agencies are neither better positioned to acquire nor possess better information than the industry participants with respect to the benefits and costs of alternative industry structures. ${ }^{32}$ In fact, the agencies must rely largely on

\footnotetext{
${ }^{32}$ Woroch (1991) draws a similar conclusion about the ability of regulators to search for and find the socially optimum market structure.
} 
industry-supplied information. ${ }^{33}$ Removing the portion of uncertainty owing to regulation would allow the future structure of telecommunications to be guided more by innovation and low-cost technologies than by regulatory decree.

Complete deregulation would remove the portion of uncertainty owing to regulation, but it would also be too abrupt and politically infeasible. Instead, we envisage a period of transitional deregulation in which pricing flexibility is granted to LECs and restrictions on intraLATA and interLATA competition are relaxed. In addition, restrictions in the 1984 Cable Act barring LECs from video services are lifted. As the industry moves toward some equilibrium configuration, regulators should discourage situations where expensive resources are being duplicated wastefully. In addition, regulators may want to continue pursuing the goal of universal service, a goal that will be made more difficult in a competitive environment where cross subsidies cannot be hidden. The transition will afford an opportunity to devise more efficient means of subsidies through the use of broad-based taxes that will not distort prices the way that current pricing and access charges do. (Panzar and Wildman, 1993) Regulators might also keep a watchful eye on rural areas to see that they continue to receive narrowband service if broadband is too costly. If subsidies to rural areas are needed even for narrowband service, then the subsidies should be targeted to low-income users instead of all rural users, as such subsidies currently are.

\subsection{Errors of Omission and Errors of Commission}

Analyzing whether the LECs ought to continue facing status quo regulation brings to mind a parallel experience from earlier in this century. While this is not the place to review regulatory experiences in various industries, it is instructive to consider decisions by Congress and the Interstate

\footnotetext{
${ }^{33}$ Theoretical literature over the past decade on optimum regulatory design has stressed the asymmetry of information between the firm and regulator. A key finding is that the firm can take advantage of its superior information to earn rents. The efficiency attained through regulation implied by the policies in Table 1 under complete information are not achievable. See, for examples, Besanko and Sappington (1986) or Laffont and Tirole (1993).
} 
Commerce Commission when trucks challenged railroads for some traffic over particular routes. The conditions of the Depression and the prevailing understanding of the strengths and limitations of governments and markets led to regulation. Markets were viewed as fragile, subject to break-downs and filled with pockets of market power. The result was to bring a variable-cost technology--trucks-under the regulatory umbrella. Unlike the case of railroads, the fixed costs of trucking were not sunk. Yet the natural monopoly regulatory paradigm was adopted. Inter-modal competition was "managed" via entry and exit restrictions and price regulation.

The costs of prohibiting intermodal mergers, of limiting entry into new markets, of delaying the introduction of new services at lower prices, and of nearly bankrupting the railroad industry present some lessons for telecommunications today. Like the railroad, the local exchange carrier is vulnerable to new entrants -- but this time regulators are not trying to balance the interests of the firms competing in this infrastructure industry. Entry is actively encouraged in many jurisdictions. The handwriting is on the wall. The question is whether deregulation is deemed acceptable before core customers are left with tons of copper wire.

The decision to continue current regulation involves accepting the hypothesis that LECs are natural monopolies over their current offerings (POTS, BUSINESS and MESSAGE) and that CATVs' average incremental cost of POTS is not less than the same cost for the LECs. While the probability that this hypothesis is correct is unknown, developments since 1982 have significantly lessened both the likelihood and the costs of transitional regulation. To illustrate the changing perceptions of the benefits and costs of the status quo, consider the implications of making a policy error. Using some concepts from statistics helps to formalize the concepts.

The acceptance or rejection of a statistical hypothesis is based on a sample of observations. In the absence of full information, a sample of data is used to decide whether to accept $\mathrm{H}_{\mathrm{O}}$ (the null hypothesis) or the alternative hypothesis, $\mathrm{H}_{\mathrm{A}}$. Thus, there is some probability that the decision will 
be incorrect. There are two types of errors: accepting $\mathrm{H}_{\mathrm{A}}$ when $\mathrm{H}_{\mathrm{O}}$ is true or accepting $\mathrm{H}_{\mathrm{O}}$ when $\mathrm{H}_{\mathrm{A}}$ is true. These are referred to as Type I and Type II errors, respectively (Freund, 1962, p. 238240). The matrix in the table below shows these errors:

Table 2. Type I and Type II Errors

\begin{tabular}{llll|}
\multicolumn{1}{c}{} & \multicolumn{1}{c}{$\mathrm{H}_{\mathrm{O}}$ is True } & \multicolumn{1}{c}{$\mathrm{H}_{\mathrm{A}}$ is True } \\
\cline { 2 - 3 } Accept $\mathrm{H}_{\mathrm{O}}$ & Correct decision & Type II error \\
\cline { 2 - 3 } Accept $\mathrm{H}_{\mathrm{A}}$ & Type I error & Correct decision \\
\cline { 2 - 3 } & &
\end{tabular}

$\mathrm{H}_{\mathrm{O}}=$ "LECs are natural monopolies over their current offerings and CATVs' average incremental cost of POTS is not less than the LECs' average incremental cost of POTS"

$\mathrm{H}_{\mathrm{A}}=$ "LECs are not natural monopolies over their current offerings or CATVs' average incremental cost of POTS is less than the LECs' average incremental cost of POTS"

The criterion for testing a hypothesis requires the formulation of an alternative. Here consider the null hypothesis, $\mathrm{H}_{\mathrm{O}}$, stated above. If accepted, and it is true, then the correct policy decision will be made -- to continue, more or less, with status quo regulation. However, continuing status quo regulation is not best for society if $\mathrm{H}_{\mathrm{A}}$, stated above, is correct. ${ }^{34}$

Just as with the construction of statistical tests, the development of public policies in the presence of uncertainty involves identifying and selecting the probabilities of committing these two types of errors. Similarly, the criterion for accepting or rejecting $\mathrm{H}_{\mathrm{O}}$ can be altered, thus changing the probability of committing one or the other error. Another statistical parallel is that the sample size itself can be increased, thus reducing the likelihood of an error.

When the MFJ was established, the prevailing conditions influenced both the agreement and subsequent decisions related to the MFJ. Given the information at the time, the null hypothesis was

\footnotetext{
${ }^{34}$ Sidak (1993) makes an argument similar to ours in his recent review of telecommunications policy issues.
} 
"LECs are natural monopolies," and avoiding a Type I error was given substantial weight. A high hurdle of proof was needed to reject $\mathrm{H}_{\mathrm{O}}$ and accept $\mathrm{H}_{\mathrm{A}}$. A Type I error meant deregulation when continuing current regulation would be best for society. The perceived costs of a Type I error were the political and economic consequences associated with deregulating a natural monopoly.

What about perceptions regarding a Type II error? Mislabelling LECs as natural monopolies and continuing the status quo when removing restrictions would be best for society was not viewed as involving substantial costs. The technologies and demand patterns at the time suggested that even if incumbents were not natural monopolies, continuing regulation would not deny citizens the fruits of technological change. Moreover, the likelihood of entry appeared remote to most participants.

Policy-makers want to avoid negative surprises. They do not want to commit a Type I error-accepting a policy change $\left(\mathrm{H}_{\mathrm{A}}\right)$, when continuing status quo regulation is best for society $\left(\mathrm{H}_{\mathrm{O}}\right)$. If a policy change leads to problems, the negative outcomes are visible and result in criticisms of the policy mistake. On the other hand, if a Type II error is committed, no one observes the benefits that were lost when the policy change was rejected. This asymmetry tends to make decision-makers overemphasize the importance of avoiding Type I errors.

Greenwald and Sharkey (1989) noted that "...preventing the entry of regulated firms into unregulated markets may deprive those markets of potentially vigorous competitors. These arguments are potentially the most significant costs of regulation, but at the same time those that are most difficult to appraise, either theoretically or empirically." (p. 325, [emphasis added]) After recognizing the lost benefits from Type II errors, Greenwald and Sharkey did not attempt to address them further. Because the decision whether to continue status quo regulation ought to minimize the sum of the costs of Type I and Type II errors, the latter warrant more attention.

There is a trade-off between Type I and Type II errors: the greater the evidence required before accepting $\mathrm{H}_{\mathrm{A}}$, the less likely is the possibility of a Type I error. That is, the more stringent 
the tests before accepting $\mathrm{H}_{\mathrm{A}}$, the less likely that current regulation will be discontinued. From the standpoint of public policy development, the emphasis on avoiding a Type I error places the burden of proof on arguing that LECs are not natural monopolies or CATVs' average incremental costs are higher. Local exchange services are presumed to be a natural monopoly until proven otherwise. If greater weight were given to avoiding a Type II error (because of the costs associated with foregone opportunities), the burden of proof would be placed on asserting that a natural monopoly exists in the local exchange over the current offerings and that the CATVs have higher incremental costs for POTS than the LECs.

There are two changes over the last decade that could encourage policy-makers to now reject $\mathrm{H}_{\mathrm{O}}$ and accept $\mathrm{H}_{\mathrm{A}}$ so that transitional deregulation would be best. First, the weights to be given to Type I and Type II errors could have changed--reducing the burden of proof on those maintaining that the local exchange is not a natural monopoly. The direct and indirect costs of continuing regulation are higher than in the past. ${ }^{35}$ Expenses incurred by regulatory commissions are only a small part of the costs of regulation. Incumbents and potential entrants understand that regulatory decisions rather than developments in the marketplace affect their future cash flows. So substantial resources are devoted to blocking the initiatives of other firms. The resulting rent-seeking activity dissipates net revenues and corporate energies. Managerial attention is diverted from research laboratories to regulatory hearing rooms. The scientific discovery process becomes less important (at least in the short run) than the regulatory review process and legislative hearings.

The second change that could encourage policy-makers to reject the status quo is that there is now more than a decade's worth of additional information. In statistical terms, the sample size is larger, which reduces the likelihood of either type of error. Some of the additional information is in the form of a better understanding of the implications that contestability and sustainability have for

\footnotetext{
${ }^{35}$ Greenwald and Sharkey (1989) succinctly categorize the costs of regulation.
} 
industry performance. This better understanding is what has been brought to bear on the issue in Section $2 .^{36}$ The null hypothesis has been expanded from "LECs are natural monopolies" to "LECs are natural monopolies and their average incremental cost of POTS is lower than CATVs' average incremental cost of POTS." Entrants using another technology and providing another service (spectrum-use for mobile service) are going to have low incremental costs for entering POTS as well (especially once the unbundling/pricing issues are resolved for switching services). Furthermore, international developments provide us with data on scenarios in other nations, such as the United Kingdom.

This new information points in the direction of rejecting $\mathrm{H}_{\mathrm{O}}$. Of course, this status quo is not fixed in cement. Different states have adapted to the changing technological conditions by introducing greater flexibility into the pricing process, rejecting arbitrary cost allocation manuals, and promoting network modernization. The direction being taken by regulation is clear. However, a national policy change at this time would represent a recognition that the costs of a Type II error are higher than in the past, and the cost of a Type I error lower than in the past.

\footnotetext{
${ }^{36}$ It is not a historical accident that Kahn's 1971 synthesis of the regulatory literature dominated the field for a decade and a half. The Bell Journal of Economics (renamed the Rand Journal of Economics in 1984) was first published in 1970: the field of industrial organization/regulatory economics was about to be transformed as theorists began to investigate the causes and consequences of different regulatory incentive mechanisms. The Journal became the fifth most-cited economic journal -- reflecting an unparalleled rise to prominence in the field. Fundamental discoveries first appeared in technical journals. After a decade and a half, a number of comprehensive volumes were published which incorporated these new analytical approaches to regulatory issues, especially those associated with multiproduct firms, sustainability and contestability, information asymmetries, and incentive mechanisms. These include those already referenced above and Bonbright, Danielson and Kamerschen (1988), (an update of the much earlier Bonbright classic); Crew and Kleindorfer (1986), Sherman (1989), Spulber (1989), and Waterson (1988). Other more specialized books also appeared during this period. In addition, the Journal of Regulatory Economics joined the RAND Journal as another outlet for research on regulation. Our observations about the sustainability of price structures is based on the new results developed over the past two decades and consolidated over the past decade.
} 


\section{Concluding Observation}

Greenwald and Sharkey (1989) argued that "partial deregulation and regulatory reform can lead to substantial social benefits, even in industries which retain some natural monopoly characteristics." (p. 337). We extend their reasoning by re-examining whether LECs are natural monopolists once additional services are added to the relevant set. The stylized cases are not intended to be a proof by elimination and contradiction. In a world of uncertainties, little can be rigorously proven in the policy arena. However, we are convinced that the framework establishes a chain of reasoning which would place a far greater burden of proof those on favoring the regulatory status quo. 


\section{Acknowledgements}

The authors are Professors of Economics at the University of Florida and the University of Wyoming. We are very grateful to Curtis Cramer, Joseph Dwyer, Richard Cabe, David Sappington, Gregory Sidak and two anonymous referees for comments on this work. Errors of omission and commission reside with us alone. Our conclusions do not necessarily reflect the views of the sponsors of the Public Utility Research Center (Florida) or the Public Utility Research and Training Institute (Wyoming). This paper was presented at the Southern Economic Association meeting, November 1994. 


\section{References}

Bain, John S. 1992. "Fiber Bypass: The Emerging Competition in Local Transport." Raymond James \& Associates, St. Petersburg, FL (August).

Baumol, W. J., J. C. Panzar, and R. D. Willig. 1982. Contestable Markets and the Theory of Industry Structure. New York: Harcourt Brace Jovanovich.

Baumol, W. J., and J. G. Sidak. 1994. Toward Competition in Local Telephony. Boston, Mass.: MIT Press.

Berg, S. V., and J. Tschirhart. 1988. Natural Monopoly Regulation: Principles and Practice. U.S.A.: Cambridge University Press.

Besanko, David, and David E. M. Sappington. 1986. "Designing Regulatory Policy with Limited Information." In Fundamental of Pure and Applied Economics, 20, New York: Harwood.

Bonbright, James C., Albert L. Danielson, and David R. Kamerschen. 1988. Principles of Public Utility Rates. Arlington, VA: Public Utility Reports, Inc.

Braeutigam, R. R. 1989. "Optimal Policies for Natural Monopolies." In Handbook of Industrial Organization, Vol. 2., edited by R. Schmalensee and R. Willig. Amsterdam: North-Holland.

Braeutigam, R. R., and J. C. Panzar. 1989. "Diversification Incentives under "Price-Based" and "CostBased" Regulation." RAND Journal of Economics 20 (Autumn): 373-391.

Brennan, T. J. 1990. "Cross-Subsidization and Cost Misallocation by Regulated Monopolists." Joumal of Regulatory Economics 2 (March): 37-52.

Cabe, R. 1990. "Network Differentiation and the Prospect for Competition in Local Telecommunications." Center for Agricultural and Rural Development, Iowa State University, $1-12$.

Calhoun, G. 1992. Wireless Access and the Local Telephone Network. Norwood, MA: Artech House.

Charnes, A., W. W. Cooper, and T. Sueyoshi. 1988. "A Goal Programming/Constrained Regression Review of The Bell System Breakup." Management Science 34: 1-26.

Copeland, Basil L., and Alan Severn. 1985. "Price Theory and Telecommunications Regulation: A Dissenting View." Yale Journal on Regulation 3: 53-69.

Christensen, L. R., D. C. Cummings, and P. E. Schoech. 1983. "Econometric Estimation of Scale Economies in Telecommunications." In Economic Analysis of Telecommunications: Theory and Applications, edited by L. Courville, A. de Fontenay, and R. Dobell. Amsterdam: NorthHolland. 
Cramer, C. A. 1994. "Local Competition for Telephone Services." Review of Industrial Organization forthcoming.

Crew, Michael, and Paul Kleindorfer. 1986. The Economics of Public Utility Regulation. Cambridge, Mass.: MIT Press.

Egan, Bruce L., 1994. "Economics of Wireless Communications Systems in the National Information Infrastructure (NII)." Report to the U.S. Congress Office of Technology Assessment (September): 1-66.

Evans, D. S., and J. J. Heckman. 1983. "Multiproduct Cost Function Estimates and Natural Monopoly Tests for the Bell System." In Breaking Up Bell, edited by D. S. Evans. Amsterdam: North Holland.

Faulhaber, G. R. 1975. "Cross-Subsidization: Pricing in Public Enterprises." American Economic Review 65: 966-77.

Faulhaber, G. R., and S. B. Levinson. 1981. "Subsidy-Free Prices and Anonymous Equity." American Economic Review 71: 1083-91.

Freund, J. E. 1962. Mathematical Statistics. Englewood Cliffs, N.J.: Prentice-Hall.

Gabel, D., and M. Kennet. 1991. "Estimating the Cost Structure of the Local Telephone Exchange Network." National Regulatory Research Institute, NRRI 91-16, 1-149.

Gabszewicz, J. J., A. Shaked, J. Sutton, and J. F. Thisse. 1986. "Segmenting the Market: The Monopolist's Optimal Product Mix." Journal of Economic Theory 39: 273-89.

Greenwald, B. C., and W. W. Sharkey. 1989. "The Economics of Deregulation of Local Exchange Telecommunications." Journal of Regulatory Economics 1: 319-339.

Gross, Donaldson, Lufkin, and Jennette. 1992. Local Telephone Competition. Report No. 1226863 (May 18).

Huber, P. W. 1993. "Telephones, Competition, and the Candice-Coated Monopoly." Cato Review of Business \& Government Regulation 2: 34-43.

Huber, P. W., M. K. Kellogg, and J. Thorne. 1992. The Geodesic Network II: 1993 Report on Competition in the Telephone Industry. Washington, D. C.: The Geodesic Company.

Jamison, Mark A. 1994. "Sustainable Prices and Cross-Subsidization in Monopolies." Working paper, Sprint Communications, Kansas City, (March).

Johnson, Leland L., 1994. Toward Competition in Cable Television. Cambridge, Mass.: MIT Press.

Kahn, A. E., and W. B. Shew. 1987. "Current Issues in Telecommunications Regulation: Pricing." Yale Journal on Regulation 4: 191-256. 
Kahn, A. E., and W. E. Taylor. 1994. "The Pricing of Inputs Sold to Competitors: A Comment." Yale Journal on Regulation 11 (no. 1, Winter): 225-240.

Karpinski, Richard, 1994. "What's Next for Cable...POTS and Beyond." Telephony 25 (July): 24-27.

Kinzler, Frederick W., L. Keta Ruiz, and Glenn A. Woroch. 1992. "Deployment of Urban Fiber Rings by CAPs and LECs." Working paper, GTE Laboratories, Waltham, MA, (August).

Laffont, Jean-Jacques, and Jean Tirole. 1993. A Theory of Incentives in Procurement and Regulation. Cambridge, Mass.: MIT Press.

Mirman, L. J., Y. Tauman, and I. Zang. 1985. "Supportability, Sustainability, and Subsidy Free Prices." RAND Journal of Economics 16: 114-26.

Mitchell, B. M., and I. Vogelsang. 1991. Telecommunications Pricing: Theory and Practice. New York: Cambridge University Press.

Panzar, J. C. 1980. "Sustainability, Efficiency, and Vertical Integration." In Regulated Industries and Public Enterprise, edited by B. Mitchell, and P. R. Kleindorfer. Lexington, Mass.: Lexington Books.

Panzar, John C., and Steven S. Wildman, 1993. "Competition in the Local Exchange: Appropriate Policies to Maintain Universal Service in Rural Areas." Northwestern University, (September).

Panzar, J. C., and R. D. Willig. 1977. "Free Entry and the Sustainability of Natural Monopoly." Bell Journal of Economics 8 (1): 1-22.

Parsons, Steve G. 1994. "Seven Years after Kahn and Shew: Lingering Myths on Costs and Pricing Telephone Service." Yale Journal on Regulation 11 (Winter): 149-170.

Riordan, Michael H. 1992. "Regulation and Preemptive Technology Adoption." RAND Journal of Economics 23 (no. 3, Autumn): 334-349.

Roeller, L. H. 1990. "Proper Quadratic Cost Functions with an Application to the Bell System." Review of Economics and Statistics 72: 202-210.

Sidak, J. Gregory, 1993. "Telecommunications in Jerico: A Review Essay." California Law Review 81: 1209-1239.

Shaked, A., and J. Sutton. 1982. "Natural Oligopolies." Econometrica 51: 1469-84.

Sharkey, W. W. 1982. The Theory of Natural Monopoly. New York: Cambridge University Press.

Sherman, Roger. 1989. The Regulation of Monopoly. New York: Cambridge University Press. 
Shin, R. T., and J. S. Ying. 1992. "Unnatural Monopolies in Local Telephone." RAND Journal of Economics 23(2): 171-183.

Spulber, D. F. 1989. Regulation and Markets. Cambridge, Mass.: The MIT Press.

Spulber, D. F. 1989. "The Second Best Core." International Economic Review 30: 623-31.

Sutton, J. 1986. "Vertical Product Differentiation: Some Basic Themes." American Economic Review, Papers and Proceedings 76: 393-8.

Tschirhart, J. 1989. "Partial Regulation of Natural Monopoly." In Political Economy of Government Regulation, edited by Jason Shogren. Norwell, Mass.: Kluwer Academic Press.

Waterson, Michael. 1988. Regulation of the Firm and Natural Monopoly. Oxford: Basil Blackwell.

Woroch, Glenn A. 1991. "Technology, Regulation, and the Emergence of Competitive Access Providers." (October), presented at 19th Telecommunications Policy Research Conference, Solomon, MD, 1991.

Zajac, E. E. 1972. "Some Preliminary Thoughts on Subsidization." Proceedings of a Conference on Communication Policy Research, Washington, D.C. 